\title{
Advanced Chronic Obstructive Pulmonary Disease: Innovative Approaches to Palliation
}

\author{
GRAEME M. ROCKER, M.H.Sc., D.M., ${ }^{1,2}$ TASNIM SINUFF, M.D., Ph.D., ${ }^{3}$ \\ ROBERT HORTON, M.D. ${ }^{2}$ and PAUL HERNANDEZ, M.D.C.M. ${ }^{1}$
}

\begin{abstract}
By the year 2020, chronic obstructive pulmonary disease (COPD) will be the third leading cause of death globally. While there have been consistent calls for increased palliative care involvement in the care of patients with advanced COPD, these calls should be based on empirical evidence that such an approach improves the symptom burden and poor quality of life associated with advanced COPD. Rather than reviewing the traditional treatments of airflow obstruction and palliative measures familiar to the palliative care community, we will focus on some novel approaches to the management of patients with advanced COPD from the perspective of clinicians involved in end of life care provision and research. By combining the clinical and research skills of pulmonologists and palliative medicine specialists we can advance the care of patients with this progressive and incurable disease.
\end{abstract}

\section{INTRODUCTION}

$\mathbf{C}$ HRONIC OBSTRUCTIVE PULMONARY DISEASE (COPD) is an incurable and progressive respiratory disease. Symptoms in late stages are often worse than those in patients with advanced lung cancer. ${ }^{1-3}$ The term COPD should be understood to equate to and include other terms in common usage such as chronic bronchitis and emphysema, all sequelae of smokingrelated, inflammation-driven destruction of lung parenchyma. As one of the most common chronic diseases, COPD is a major cause of morbidity and mortality. In the United States, some 250,000 patients with advanced COPD die each year. It accounts for $4 \%$ of deaths annually in Canada and will result in more than 20,000 deaths per year by $2018 .^{4,5}$ Globally, COPD will be the third leading cause of death by $2020 .^{6}$
The final years for patients with advanced COPD are characterized by progressive functional decline, poor quality of life, increasing dependency on informal caregivers and on the health care system. ${ }^{7}$ Ultimately, many are faced with incapacitating breathlessness. ${ }^{3,8-11}$ Patients with advanced COPD have special palliative care needs. Patients themselves recognize these needs ${ }^{12}$ but until recently, palliative care has focused predominantly on patients with cancer. ${ }^{13}$ There have been several calls for greater involvement from palliative care services for patients with advanced COPD ${ }^{1,3,14-18}$ including a recent position statement from the American College of Chest Physicians, ${ }^{19}$ although the benefit of this type of involvement, while intuitive, has yet to be evaluated in a homogenous population of patients with COPD.

There are two key barriers between a diagnosis of advanced COPD and provision of quality end-of-life

\footnotetext{
${ }^{1}$ Division of Respirology, ${ }^{2}$ Division of Palliative Medicine, QEII Health Sciences Centre and Dalhousie University, Halifax, Nova Scotia, Canada.

${ }^{3}$ Department of Critical Care and Division of Respirology, University of Toronto, Sunnybrook Health Science Centre, Toronto, Ontario, Canada.
} 
(EOL) care: (1) the highly unpredictable disease trajectory and (2) many patients and their caregivers fail to appreciate that COPD is a life threatening disease (20). The disease trajectory differs fundamentally from that of cancer. ${ }^{21,22}$ Episodic exacerbations and incomplete recovery challenge the timing of any supportive intervention in accordance with patients' current needs. In contrast to the needs-based care approach for patients with cancer, studies in the United States and Canada, including SUPPORT (the Study to Understand Prognoses and Preferences for Outcomes and Risks of Treatments) have demonstrated that hospitalized patients with advanced COPD are more likely to receive technological interventions (without establishing prior life support preferences). Moreover, they often die in an intensive care unit (ICU) setting, die with greater symptom burden, 16,20 and with less input from other services. $1,7,21,23,24$ Other impediments to provision of effective palliative care for patients with advanced COPD include patients' limited understanding of treatment options, barriers to effective communication due to attitudes of patients, physicians, and other caregivers, ${ }^{25-29}$ and our limited ability to judge when palliative care services may be helpful. ${ }^{30,31}$

Patients with advanced COPD (and their physicians) have yet to benefit from the breadth of rigorous research studies that have been conducted among their cancer counterparts. ${ }^{2,13,30,32}$ While we accumulate this research knowledge base we need to break down the barriers to effective palliative care for patients with advanced COPD. To do so, perhaps we need to accept the uncertain prognosis and focus instead on how to tailor high-quality palliative care to individual patient needs as COPD progresses.

\section{UNDERSTANDING THE PROGRESSION OF ADVANCED COPD AND DETERMINING WHO NEEDS PALLIATIVE CARE}

Compared to cancer, in which the terminal phase is often clear to both physicians and patients, ${ }^{33}$ prognoses for individual patients with COPD are notoriously inaccurate; only dementia has a less certain 6-month prognosis among the other 19 reasons for hospice referral in the United States. ${ }^{34}$ "Common-sense guidelines" have been proposed to identify patients with advanced lung disease and minimal cardiopulmonary reserve who may benefit from hospice palliative care ${ }^{15}$ (e.g., patients who, despite an adequate trial of optimum and acceptable available treatment, have a chronic lung disease that has progressed to the point that the patient may die at any time because of an ordinary intercurrent illness, such as bronchitis or pneumonia).These patients can be expected to benefit from the specialized services offered by hospice programs because of distressing symptoms or a severely limited performance status; the patient accepts that death may be near and does not want to suffer needlessly. ${ }^{15}$

To help identify patients with COPD and a significant risk of death within one year, Hansen-Flaschen ${ }^{34}$ proposed a profile, extrapolated from earlier studies of various predictors of mortality (Table 1). ${ }^{22,35-38}$

Table 1. Predictors of Increased Mortality for Patients with Advanced COPD

\begin{tabular}{|c|c|c|}
\hline $\begin{array}{l}\text { Increased risk of death in } \\
\text { next } 12 \text { months (proposed) }\end{array}$ & $\begin{array}{l}30-40 \% \text { 6-month } \\
\text { mortality } 24,39,40\end{array}$ & $30-40 \%$ 2-year mortality ${ }^{41}$ \\
\hline $\begin{array}{l}\text { 1. Best } \mathrm{FEV}_{1}<30 \% \\
\text { predicted } \\
\text { 2. Increasing dependency } \\
\text { on caregivers }\end{array}$ & $\begin{array}{l}\text { Using SUPPORT criteria: } \\
\text { two of the following for } \\
\text { hospitalized patients: }\end{array}$ & $\begin{array}{l}\text { Highest quartile on BODE } \\
\text { index i.e. a score of } 7-10 \\
\text { (see scores in parentheses } \\
\text { below) }\end{array}$ \\
\hline \multicolumn{3}{|l|}{ 3. Activity limited to a few } \\
\hline steps without rest & 1. Baseline $\mathrm{PaCO}_{2}>$ & Body mass index $(\mathrm{B})>21$ \\
\hline 4. Depression & $45 \mathrm{~mm} \mathrm{Hg}$ & $(0)$ or $\leq 21$ \\
\hline 5. No spouse & 2. Presence of cor & Airflow obstruction $(\mathrm{O})$ \\
\hline \multirow{3}{*}{$\begin{array}{l}\text { 6. Recurrent } \\
\text { hospitalization in the } \\
\text { previous year }\end{array}$} & pulmonale & $\mathrm{FEV}_{1}$ of $36-49 \%$ (2) or \\
\hline & 3. $\mathrm{FEV}_{1}<0.75$ liters & $<35 \%$ \\
\hline & 4. Previous episode of & Dyspnea (D) MMRC ${ }^{\mathrm{a}}$ score \\
\hline \multirow{2}{*}{$\begin{array}{l}\text { 7. Associated chronic } \\
\text { comorbid illness. }\end{array}$} & respiratory failure in the & of $3(2)$ or $4(3)$ \\
\hline & last 12 months & $\begin{array}{l}\text { Exercise capacity (E) (walks } \\
\quad<150-249 \mathrm{~m} \text { in } 6 \text { min (2), or } \\
\quad<149 \mathrm{~m} \mathrm{(3)}\end{array}$ \\
\hline
\end{tabular}

${ }^{a}$ MMRC: Modified Medical Research Council score of 3 indicates patient stops for breath at 100 yards or after a few minutes on level ground, MMRC score of 4: patient is too breathless to leave the house or is breathless dressing or undressing.

$\mathrm{FEV}_{1}$, Forced expiratory volume in 1 second. 
Others have proposed use of the BODE index, based on body-mass index (B), airflow obstruction (O), dyspnea (D), and exercise capacity (E). ${ }^{41}$ However, even patients with the highest BODE index quartile scores had a 30\%-40\% 2-year mortality. ${ }^{41}$ In Canada we emulated the criteria used in SUPPORT ${ }^{39}$ to define advanced COPD (Table 1). In our five-center study that included 118 patients with advanced $\mathrm{COPD}^{24,40}$ 6month mortality was $40 \%$. These results are similar to those from the United States ${ }^{39}$ and Europe, where recently mortality risk has been shown to increase with the frequency of each hospital admission for a COPD exacerbation. ${ }^{42}$ These studies suggest that a combination of some simple measures of disease severity can provide a reasonable indication of a likely poor outcome within the next year.

In Canada there is nothing comparable to the U.S. hospice benefit program. Hence, we need to move beyond the traditional boundaries of palliative care. ${ }^{43,44}$ Rather than focus on a short term prognosis as the means to gain access to quality palliative care for patients with advanced COPD we should move toward interventions based on need. ${ }^{2,31}$ Determining patients' needs requires a mixed methods approach and increasingly we are seeing the value of qualitative studies to inform changes to models of care.

\section{DETERMINING PATIENTS' NEEDS IN ADVANCED COPD}

Studies using qualitative methods to focus on needs of patients with advanced COPD have been conducted in the United States, Canada, and Europe. For example, in the United Kingdom, analysis of postbereavement interviews of family members after 209 deaths resulting from COPD, clearly indicated that there was insufficient surveillance and inadequate provision of both primary and specialist care in the year before death. ${ }^{10}$ In the United States, Curtis and colleagues ${ }^{45}$ have described the needs for spiritual support, for physicians skilled in communication who can inform patients about their prognosis and what dying might be like. We recently reported the key elements of quality of EOL care identified by 434 seriously ill hospitalized patients in Canada (including 118 with COPD) ${ }^{40}$ These patients with advanced COPD at high risk of 6-month mortality (and their caregivers where available) completed questionnaires to identify aspects of EOL care most important to them and how satisfied patients and caregivers were with those aspects of care $^{24,46}$ For 118 patients with advanced COPD, the most important unmet needs concerned symptom re- lief, not being a burden to family, receiving adequate information (including benefits and risks of treatments), having a physician available to discuss COPD and answer questions in a way that is understood, and having adequate health services after discharge from hospital. ${ }^{24}$ Similar themes (poor symptom control, need for information, the impact of symptoms on patients' and on caregivers' lives) have emerged from studies of advanced COPD in the United Kingdom. ${ }^{3,9}$

\section{SYMPTOM RELIEF: DYSPNEA}

For patients with advanced COPD, dyspnea is the most distressing and prevalent symptom. In SUPPORT, $75 \%$ of patients reported serious dyspnea. ${ }^{20} \mathrm{Ul}-$ timately dyspnea may be incapacitating. ${ }^{3,8,11}$ Dyspnea is the symptom least well palliated by traditional approaches. ${ }^{10} \mathrm{~A}$ range of interventions to relieve dyspnea include: use of standard medical therapy with bronchodilators, ${ }^{47}$ long-term oxygen, and others with variable benefit and accessibility (e.g., lung volume reduction surgery), ${ }^{48}$ pulmonary rehabilitation, ${ }^{49}$ and use of opioids. ${ }^{50}$ Despite these approaches, only $50 \%$ of patients with end-stage COPD benefit from any such intervention ${ }^{10}$ and many live (and die) with incapacitating breathlessness. ${ }^{11}$

Advances in strategies to palliate dyspnea for patients with cancer will almost certainly help others with chronic conditions in which dyspnea is a key symptom. Moving beyond individual therapies, Booth and colleagues $^{51}$ in the United Kingdom have described a "breathlessness intervention service" (BIS) and its impact on patients living with intractable dyspnea. The BIS service model as currently described is based on four consultations. First, a patient meets with a physician and physiotherapist. Severity of dyspnea and quality of life is assessed and recorded. Patients are asked to indicate three goals that they would like to achieve though the BIS. Needs of their informal caregivers are assessed at the same time. The second consultation occurs approximately a week later and a tailor-made exercise program is planned. Patients receive advice about breathing exercises, use of fans, positioning, and help with usual activities. Referrals to others specialists are made at this visit. The third assessment is made by the physiotherapist at approximately 3-4 weeks by telephone to the patients home to check on progress, answer questions, etc. The final assessment occurs 4-6 weeks after the initial assessment to allow for feedback, symptom measurement, and ongoing support plans.

In planning the BIS, the investigators used the Medical Research Council framework for the evaluation of 
complex interventions to improve health ${ }^{52}$ as a guide to program development. In 2006 Booth and colleagues ${ }^{51}$ reported results from a phase 1 qualitative study that emphasized the value of understanding the perspectives of participants in the research program and making improvement to the provision of a multifaceted service based on patient feedback. For example, patients and families reported on the value of being listened to and empathized with, on the value of having someone they could call when frightened, and on the importance of "looking at what was possible rather than dwelling on what had been lost." 51 A dropin service, written advice, and continuing education were other recommendations for ongoing development of the service. Even the recognition by the BIS team that caregivers of dyspneic patients were doing all that they could proved valuable according to the feedback received from family members. Providing education about dyspnea was important in the development of effective patient coping strategies. Patients and families valued the recognition of breathlessness as an important symptom, as common as pain, but a symptom that receives less attention in general than pain, with fewer educational resources and less public understanding. ${ }^{51}$ It will be important to repeat these promising studies in other settings.

To treat dyspnea effectively we need research studies that measure this troubling symptom in a meaningful and reproducible way and use these measures and the information gained to intervene with strategies in a clinical setting that can help reduce symptom burden, and thus improve quality of life. In a recent systematic review of the measurement of breathless, Bausewein and colleagues have recommended "combining a single-dimensional scale (e.g. visual analogue scale [VAS]) with a disease-specific scale (where available) or a multidimensional scale in conjunction with other methods (such as qualitative techniques) to gauge psychosocial and informal caregiver distress for the assessment of breathlessness in advanced disease. ${ }^{53}$ The attraction of such an approach is the recognition that dypsnea is, in effect, a family symptom, affecting both patients and their informal caregivers alike. As clinicians in the field we should become more familiar with the available measurement tools and strategies that help patients and caregivers cope with disabling symptoms. Several tools are available and U.K. readers may be more familiar with the St. George's Respiratory Questionnaire. In terms of precise measurement of dyspnea, Bausewein and colleagues $^{54}$ in their systematic review favored the Chronic Respiratory Disease Questionnaire (CRQ). This instrument has also been used extensively in
COPD research and has proven reliability, validity, and longitudinal responsiveness. Responsiveness is greater for the self-administered version of CRQ. ${ }^{54}$ The CRQ is a 20-item disease-specific quality-of-life questionnaire. The questions are divided into four domains: dyspnea, fatigue, emotional functioning, and mastery. Each item is scored on a 7-point scale ranging from 1 indicating maximal impairment to 7 indicating no impairment. The dyspnea subscale consists of 5 questions that are individualized, i.e., the patient chooses from a list five activities that cause the greatest shortness of breath and then rates the severity of the dyspnea related to these activities on the initial and subsequent administration of the CRQ. The results are expressed as a mean score for each domain and a mean overall score indicating disease specific quality of life. The minimally important difference in mean score in order to document a significant change in response to therapy or intervention is $0.5 .^{55}$ The CRQ can be used repeatedly in the same patient over time. ${ }^{56}$ The CRQ has undergone several recent appraisals ${ }^{54,56-59}$ and remains one of the most widely used tools in assessment of chronic respiratory disease. ${ }^{56,57}$

When considering novel strategies to improve palliation of dyspnea, we need to consider interventions that go beyond conventional approaches to managing severe airflow obstruction. The value of a fan to direct cooler air to the face has been recognized for 20 years. ${ }^{60}$ Traditional approaches involving bronchodilators and long-term oxygen for hypoxemic patients should be familiar to the palliative care community and are discussed in detail elsewhere (for a useful and easily accessible source please see 〈www. COPDguidelines.ca $\rangle$ ). Additional measures should be implemented when there is good empirical evidence to support their use, and not just in terminal stages of lung disease. For example, opioids are an important addition to the treatment of dyspnea in the patient with severe COPD maximally treated with bronchodilators and other therapies: this role has been recognized in professional society position statements on COPD. ${ }^{61}$ A number of randomized trials and a recent meta-analysis $^{50}$ suggest that oral opioids reduce the sensation of dyspnea although use is associated with some side effects. For example, a randomized trial of sustained release morphine for 4 days showed reduced dyspnea scores but increased constipation despite laxative treatment. ${ }^{62}$ The meta-analysis also suggests that while oral and parenteral opioids are effective, ${ }^{50}$ nebulized opioids are ineffective, ${ }^{50}$ a conclusion supported by a subsequent report in 2004.63 It is important to remember that the studies of opioids considered in the systematic review ${ }^{50}$ are all short term. Nevertheless, while 
we lack long-term studies on the effects of opioids in advanced COPD, they should be considered, not only in end-of-life situations, but also for stable patients with COPD whenever breathlessness is severe and continues despite maximal bronchodilator therapy. We need to have confidence in the evidence that low dose opioids do not appear to cause significant respiratory depression. ${ }^{62}$ Several studies assessed within the systematic review ${ }^{50}$ attest to the lack of adverse effect on blood gases. A more recent study that included patients with cancer with chronic bronchitis has confirmed this finding. ${ }^{64}$ On a personal note, it was gratifying to be thanked recently for initiating morphine by a 48 -year-old with very severe COPD. A constant dose of $0.5 \mathrm{mg}$ twice daily for over a year in a woman with a markedly reduced body mass index had been life-changing. She could cope with her incapacitating breathlessness without feelings of panic. The Australian and Canadian guidelines on COPD both include guarded recommendations for considering opioids for severe dyspnea. ${ }^{61,65} \mathrm{We}$ would recommend commencing opioid therapy conservatively in such patients. A starting dose of 1-2 mg oral morphine equivalent every 4-6 hours offers a reasonable chance of initial dyspnea reduction with minimal likelihood of persistent or intolerable side effects. This starting dose can be gradually titrated to the point of satisfactory relief of dyspnea. Longer dosing intervals may be appropriate for patients with renal insufficiency. As always, clinicians should anticipate and be prepared to deal with the most commons side effects, including constipation, nausea and transient sedation. Education and reassurance of patients and caregivers around common issues of concern including, addiction, dependence, and side effects is paramount to ensure effective compliance with treatment. It is also important to point out that some patients may be prepared to tolerate some degree of incomplete symptom control in return for minimizing opioid side effects.

Patients who are experiencing an acute severe unremitting dyspnea crisis should be offered treatment with parenteral opioids. Just as patient-controlled analgesia (PCA) has become the standard of care for pain crisis of similar severity, perhaps patient controlled parenteral opioids for dyspnea crisis could offer similar benefits. To our knowledge, the potential of such treatments to manage dyspnea crisis has never been evaluated.

Palliative care clinicians will be familiar with the "Pain Ladder." Perhaps we should be incorporating a "Dyspnea Ladder" into routine assessment of our patients with progressing COPD (Fig. 1). As in any patient-physician relationship, clinicians should balance

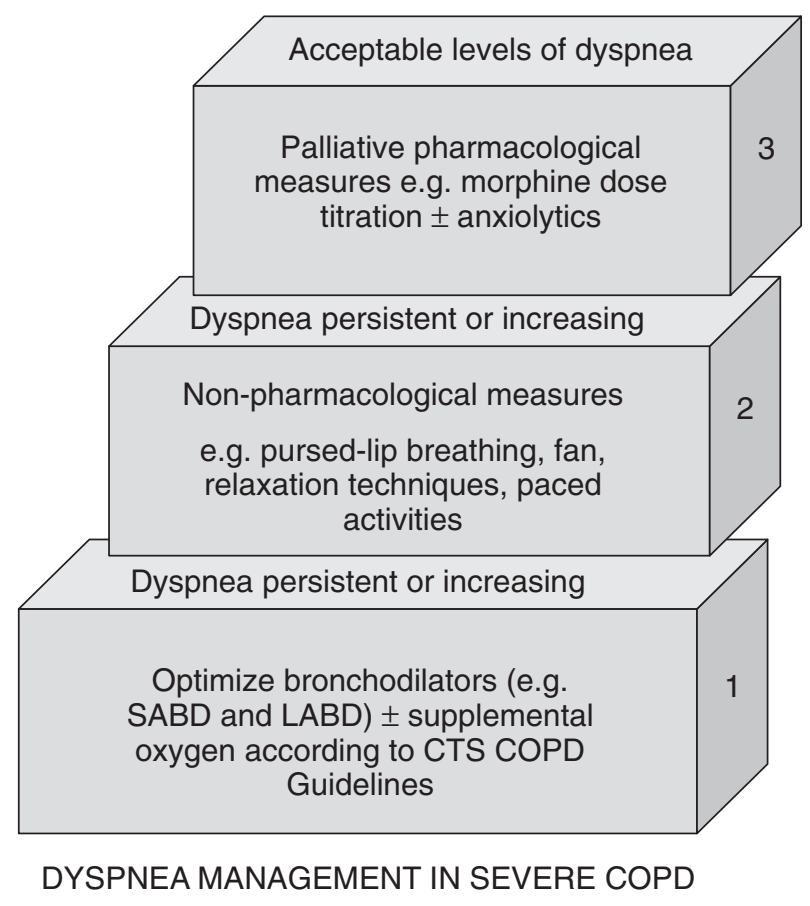

FIG. 1. The Dyspnea Ladder. SABD, short-acting bronchodilator; LABD, long-acting bronchodilator; CTS, Canadian Thoracic Society.

any benefits and side effects of any medication on an individual basis.

\section{IMPROVING COMMUNICATION, REDUCING DELAYS IN END-OF LIFE DECISION-MAKING, AND USING DECISION-AIDS}

In the United States, most patients enrolled in pulmonary rehabilitation programs welcome discussions about advanced care planning and mechanical ventilation, ${ }^{66}$ yet such discussions occurred for only $20 \%$ of patients with advanced COPD. For Canadians with COPD, surveys of Canadian pulmonologists indicate that EOL decision-making occurs late and in less than ideal settings. ${ }^{67,68}$ For some years we have known that patients with COPD request information regarding diagnosis and disease process, treatment options, prognosis, what dying might be like, and advanced care planning. ${ }^{69}$ Of 100 patients with COPD attending an outpatient setting in the United Kingdom, 98 thought these issues should be discussed with all patients ${ }^{70}$ and in another U.K. study of a mixed population of patients with life-threatening illness, patients indicated their clear willingness to discuss their prognoses, health status, and care needs. ${ }^{12}$ Nevertheless, some patients do 
not wish to discuss these issues. Physicians should be prepared and adequately trained to ascertain what their patients need. Patients often feel that their physicians do not understand their EOL care preferences ${ }^{4,66}$ and want their physicians to initiate EOL care discussions. ${ }^{71}$ Many physicians remain reluctant to do this. ${ }^{17}$

While some physicians are reluctant to initiate EOL discussions, it is a sad reality that informal caregivers in general often fail to recognize that patients might die from COPD, ${ }^{10}$ another factor that will likely limit willingness to discuss the essential but difficult topic of addressing future needs while there is an opportunity to do so. Clinicians can assist in this process in many ways. Beyond providing the much needed timely and empathetic discussion in a suitable setting, we should consider the use of decision aids to help patients who face EOL choices. ${ }^{29,72,73}$ For example, use of a structured decision-aid concerning mechanical ventilation helped 33 patients with severe COPD to make a choice; for $74 \%$ this choice was to forgo mechanical ventilation. ${ }^{72}$ Given deficiencies in the decision-making process and in quality of care for advanced COPD, appeals for increased access to palliative care services are understandable. ${ }^{1,3,15-18} \mathrm{Pal}-$ liative care physicians and pulmonologists need to ensure that these appeals are acted upon.

\section{RECOGNIZING THE IMPACT OF ANXIETY AND DEPRESSION}

Patients with advanced COPD and their partners or family members often report significant mood disturbance and sometimes even suicidal thoughts. ${ }^{18}$ Both anxiety and depression are common (affecting up to $40 \%-50 \%$ of patients) and much more prevalent than in the general population. ${ }^{74,75}$ Unfortunately both symptoms often go untreated. ${ }^{76} \mathrm{We}$ have come to a better understanding of the high prevalence of COPD-related mood disorders over the last 20 years $^{77-79}$ and roles of gender and disease severity in the onset of anxiety and depression. ${ }^{80,81}$ Earlier studies tended to report much higher prevalence of depression than anxiety. ${ }^{82}$ Treatment of depression can have beneficial effects on many aspects of living with COPD, including a positive effect on dyspnea $^{83}$ and appears to have more beneficial effects on dypnea than the use of anxiolytics. ${ }^{84,85}$ Prevalence of anxiety was nearly $50 \%$ in a large multicentre study in Scandinavia. ${ }^{81}$ Other studies have indicated depression as an independent predictor of mortality in advanced $\mathrm{COPD}^{86}$ and depression is linked to how patients make choices about potentially life-sustaining treatments. ${ }^{87}$
Given the limitations that advanced COPD imposes on social interactions, on the ability to leave one's house, on dependence on supplies of oxygen and the encumbrances imposed by oxygen tubing, we should not be surprised by a high prevalence of anxiety and depression related to social isolation. Consider some quotes from recent qualitative research. In Sweden, patients with COPD reported that they considered life as "hard work." Just to get up in the morning, get dressed and move from one room to another required all their strength. ${ }^{88}$ Patients often lived alone and those living in their own homes seldom met anyone but family, home care aides or nurses, "Then the oxygen keeps hissing and everyone asks: what is that? So you avoid going anywhere with it." 88

In the United Kingdom, data collated in postbereavement interviews from family members after 209 deaths resulting from COPD in London, clearly indicated the burden of anxiety and depression among the patients prior to their death, with low mood reported for $77 \%$ and anxiety and or panic attacks affecting $53 \%$ of patients. ${ }^{10}$ In Canada, in a series of stories about emotional vulnerability, Bailey ${ }^{8}$ described the "dyspnea-anxiety-dyspnea cycle" following an acute exacerbation of COPD as a common theme arising from interviews with 10 patients and their families. She related how simple everyday frustrations induce anxiety, more breathlessness, more anxiety, and more breathlessness with no easy way to break this cycle without seeking help and rushing to the local emergency department. Nevertheless, treatments traditionally limited to the hospital setting can also be provided in patients' homes, either by nurse practitioners or by paramedics linked to emergency services. In our own hospital we are beginning to formalize links between emergency services and palliative care to provide more effective treatment in the home setting for patients with advanced COPD (including reassurance and support, measurement of vital signs, use of aerosolized bronchodilators and oxygen) until the crisis settles. This enables patients to remain at home if that is their wish. In Europe others have described the potential value of the pulmonary rehabilitation setting as a venue to help patients with strategies that reduce anxiety and depression. ${ }^{89}$ Recognition of the psychosocial needs of patients and care providers of patients with COPD has come relatively late ${ }^{90}$ but will increasingly need to be recognized as a key facet of the provision of quality care in advanced stages of COPD.

\section{THE VALUE OF PULMONARY REHABILITATION}

The most recent joint ATS/ERS statement defines pulmonary rehabilitation as "an evidence-based, multidisciplinary, and comprehensive intervention for pa- 
tients with chronic respiratory diseases who are symptomatic. . . . Integrated into the individualized treatment of the patient, pulmonary rehabilitation is designed to reduce symptoms, optimize functional status, increase participation and reduce health care costs through stabilizing or reversing systemic manifestations of the disease." $" 91$ Participants in pulmonary rehabilitation typically attend 6 to 12 weeks of individualized exercise training, self-management education, nutritional counseling, and psychosocial support. There is substantial evidence for improvement in dyspnea, exercise tolerance, functional capacity, healthrelated quality of life, and health care utilization with pulmonary rehabilitation, particularly in COPD. ${ }^{92} \mathrm{La}-$ casse and colleagues ${ }^{93}$ performed a systematic Cochrane review that included a large number of wellconducted, randomized clinical trials of pulmonary rehabilitation in COPD. They found both statistically and clinically meaningful improvements in functional exercise capacity (as assessed using the 6-minute walk distance) and chronic dyspnea (as assessed using the dyspnea domain of the chronic respiratory questionnaire) ${ }^{93}$ Despite the substantial physiologic and clinical benefits of pulmonary rehabilitation in COPD, it is underutilized as a therapy for numerous factors, including insufficient availability of spaces and inability of patients to travel to take part in these programs because of distance or cost considerations. Studies to demonstrate whether home-based pulmonary rehabilitation is effective are needed.

For patients with advanced COPD, the combination of pulmonary rehabilitation and adjunctive therapy such as supplemental oxygen or noninvasive positive pressure ventilation (NIV) might be of some benefit. Supplemental oxygen administered via nasal cannulae can acutely improve exercise tolerance and dyspnea, even in mildly hypoxemic patients, e.g., patients who do not meet traditional criteria for longterm oxygen therapy. ${ }^{94}$ However, benefits seen in the laboratory have not played out in clinical trials that have yielded conflicting or negative results when supplemental oxygen is administered to mildly hypoxemic COPD patients, either as an adjunct to pulmonary rehabilitation or outside of this setting. ${ }^{95-97}$ The role of supplemental oxygen administered on a long-term basis to the mildly hypoxemic patient with COPD, particularly as a palliative intervention, requires further study and cannot be recommended at this time. Various modes of NIV have been shown to improve exercise tolerance and dyspnea in advanced COPD when investigated in the laboratory setting. ${ }^{98-100}$ Unfortunately, NIV when used as an adjunct to pulmonary rehabilitation has also resulted in conflicting treatment effects as measured by changes in clinically meaningful outcomes, such as health-related quality of life. ${ }^{101,102}$

Patient self-management education is a core component of pulmonary rehabilitation, which goes beyond simply providing information to patients in didactic lectures. The emphasis is on teaching patients the knowledge and skills necessary to make behavioral changes that lead to improved health outcomes. ${ }^{103}$ Just two examples of a typical education curriculum in pulmonary rehabilitation include breathing strategies to self-manage acute dyspnea and recognition and treatment of acute exacerbations using an action plan.

Symptoms of depression and anxiety are common in patients with COPD (see above). A thorough psychosocial evaluation to detect these conditions, contributing factors, and consequences are routinely performed in pulmonary rehabilitation. Supportive counseling is generally provided by most programs; either in groups or individual formats. During selfmanagement education sessions, participants learn stress management techniques to help alleviate symptoms of panic and anxiety. Patients also have the opportunity to address sensitive topics in a supportive and trusting environment, such as the impact of their illness on sexuality and their relationships with family and loved ones.

The multidisciplinary, supportive environment of the pulmonary rehabilitation program is also an ideal venue to address end-of-life issues. When asked, nearly all participants in one pulmonary rehabilitation program in the United States reported a willingness to engage in discussions about advance directives and life support with their physician. ${ }^{66}$ Despite this fact, these discussions had taken place for only $19 \%$ of patients. Seventy-eight percent of 214 programs surveyed in the United States agreed that pulmonary rehabilitation was an appropriate venue for education about advance directives; however, two thirds provided no education to their patients about advance directives. ${ }^{104}$ Although not all patients with COPD can attend pulmonary rehabilitation because of various problems with access (e.g., limited spaces, costs associated with travel, and parking), it is a missed opportunity to better educate patients with advanced COPD who do attend pulmonary rehabilitation if education regarding EOL decision-making is not incorporated into the curriculum.

\section{THE ROLE OF PATIENT SELF-MANAGEMENT EDUCATION FOR ADVANCED COPD}

The pulmonary rehabilitation setting provides opportunities to address patients' educational needs. We 
have understood for some years that patients with COPD want more information about their disease and management options ${ }^{1,24,69}$ and there is increasing interest in the role of disease specific self-management strategies, but to date, data on efficacy are sparse with mixed results. One prospective pilot study of an outpatient, structured education program for patients with COPD suggests a reduction in frequency of daily dyspnea episodes, improved knowledge about the benefits and side effects of medication, increase in the number of self-managed acute exacerbations, and a reduction in hospital length of stay. ${ }^{105}$ An RCT involving 56 patients in New Zealand demonstrated that introduction of a patient education booklet and written plan of action to manage acute exacerbations of COPD changed patient behavior leading to improved self-management skills. The study action plan failed to demonstrate any significant difference in quality of life or lung function compared to usual care, ${ }^{106}$ but the study may have been underpowered in this regard.

The efficacy of a COPD-specific self-management education program ("Living Well with COPD") was tested recently in a Canadian multicenter randomized controlled trial involving 191 patients. ${ }^{92}$ This program has seven modules. Several modules address symptom management, but none address EOL care. The current modules include educational material regarding basic information about COPD, breathing and coughing techniques, energy conservation and relaxation exercises (module 1); preventing and controlling symptoms through inhalation technique (module 2); recognition of and initiating a plan of action for an acute exacerbation (module 3); adopting a healthy lifestyle (module 4); leisure and traveling (modeul 5); a home exercise program (module 6); and understanding indications and implications of long-term home oxygen therapy (module 7). This program was presented to individual patients in their homes by trained educators over a 7-8 week period in combination with a customized action plan to manage acute exacerbations of symptoms and ongoing case management support by telephone. Most of the patients were elderly and had advanced COPD with forced expiratory volume in 1 second $\left(\mathrm{FEV}_{1}\right)$ less than 1 liter; almost half experienced severe dyspnea. Patients in the intervention group had significantly fewer emergency department and unscheduled physician visits, fewer hospital admissions, and improved health related quality of life compared to patients receiving usual care. ${ }^{92}$ As with any multifaceted intervention it was unclear which individual facet of the intervention (education, counseling, provision of support services, action plan to deal with acute exacerbations) were most effective and responsible for improved outcomes. However, few of the patients involved were at the end of life (1-year mortality in the control and intervention groups was $9 \%$ and 5\%, respectively). Moreover the lack of a module on EOL care within "Living Well with COPD" underpins the need to introduce an eighth educational module as part of programs of research, designed to improve the clinical outcomes, quality of life, and satisfaction with care of patients with advanced COPD and their caregivers.

\section{BURDENS ON INFORMAL CAREGIVERS}

While caregiver burden is often highlighted by the cancer community, ${ }^{107-110}$ measurement of burden has rarely been conducted in home-based palliative care studies. ${ }^{111}$ Moreover, where there is an intervention, there are few reports of effectiveness. ${ }^{112}$ Little is known about the effects of caring for patients with advanced COPD although recent qualitative studies have underscored the extent to which both informal caregivers and patients with COPD suffer. ${ }^{8,18,113,114}$ Caregivers have demands placed upon them related to the physical, emotional, social, spiritual, and financial aspects of caring for patients with chronic illness, compounded by a real or perceived lack of support. Patients in the late stages of COPD are often housebound yet receive little or no support from community health services. ${ }^{1,10,11}$ Fear of being a burden to family is a major concern of patients living with advanced COPD. ${ }^{24}$ Hence, we need to know whether and how much caregivers benefit from palliative care interventions provided to these patients. While some benefit has been seen in mixed populations in the United States, ${ }^{115}$ we need to assess the feasibility and efficacy of a team-managed home-based approach among caregivers of COPD patients in diverse settings.

\section{OVERVIEW OF HOME-BASED INTERVENTIONS}

While home-based interventions by palliative care teams have been available for many years for cancer patients traditionally served by palliative care, their effectiveness is uncertain. In a review of 44 studies by Higginson et al., ${ }^{111}$ the authors noted that many studies had methodological flaws and recommended randomized studies "to evaluate different types of service configuration and delivery related to specific outcomes." 111 Moreover, few such team interventions have been described for patients with COPD and those that have generally focused on providing acute homehospital services combined with nursing follow-up 
during and after acute exacerbations. ${ }^{105}$ Outcomes have been related to health service utilization, safety, and efficacy. ${ }^{105,116-118}$ Home-based interventions that have provided a combination of more comprehensive palliative care services and case management for COPD have been evaluated, although in mixed patient populations. For example, in a mixed population of patients $(n=90)$ with heart failure, COPD and cancer, a home-based intervention (50 patients) by a multidisciplinary team improved patient outcomes in dyspnea severity, anxiety, and spiritual well-being, but had no significant effect on pain, quality of life, or satisfaction with care. ${ }^{119}$ The intervention had no effect on rates of subsequent emergency room visits or hospitalization, nor on number of patients with written advanced directives. Using a hospice-based team approach, one center in the United States reported that among patients with heart failure and COPD with a 2year life expectancy, those receiving the hospice-based intervention in their homes had significantly better outcome measures of illness self-management, awareness of illness related resources, lower levels of symptom distress, greater vitality, and higher self-rated health and legal preparation for EOL compared to controls. ${ }^{120}$ Patients with COPD showed greater responses to the intervention than those with congestive heart failure. ${ }^{120}$ Meanwhile our local palliative care service is seeing increasing numbers of patients with advanced COPD. However, it remains unclear whether and to what extent the current service model meets the unique needs of this patient population. We need to determine what effect, if any, referral to the palliative care service has on patient and family outcomes related to quality of life, symptom burden, and satisfaction with care. Research studies should be designed to answer these important questions and to confirm or refute the potential benefits of an integrated home-based approach to the care of vulnerable patients with advanced COPD.

\section{ROLE OF NOINVASIVE VENTILATION IN EOL AND PALLIATIVE CARE}

The addition of noninvasive ventilation (NIV) to medical management has become the standard of care in the treatment of patients with moderate to severe exacerbations of COPD with resultant acute hypercapneic respiratory failure. In this setting NIV avoids intubation, reduces length of stay, and mortality. ${ }^{121}$ Its role in chronic stable COPD, specifically as a treatment offering potential palliation is much less certain. At the end of life, the rationale for providing assisted ventilatory support (e.g., NIV) should be grounded firmly in the ability to provide comfort and relief of dyspnea. Two early, small case series reported that NIV can reduce dyspnea and preserve patient autonomy in appropriately selected patients who declined invasive ventilatory support. ${ }^{122,123}$

Recently, there has been resurgence in the interest in assessing the effectiveness of NIV for patients who have declined mechanical ventilation. Examples of these patients include patients with advanced COPD at home or in hospice settings who develop acute respiratory failure requiring hospital admission or in patients on palliative care floors of acute care hospitals. The use and effectiveness of NIV in patients with acute respiratory failure (ARF) with a do-not-resuscitate (DNR) status remains controversial. Some of the controversy may derive from a lack of clarity about goals. NIV may be used by some patients to reverse an acute deterioration with the aim of surviving the hospitalization and returning to the prior level of function. In other cases, when NIV is used for palliation of patients at the end of life, to relieve dyspnea or allow patients time to get their final affairs in order within the context of setting agreed upon goals of care, there should be an understanding that if NIV cannot achieve the hope for aims within an accepted time frame, it can be withdrawn to allow a natural death. If the patient, caregivers, and health care team feel that benefits outweigh the burden, then NIV may have a time-limited role. ${ }^{124}$

Thus far, there have been no controlled trials of the use of NIV for patients who have declined intubation or who are receiving palliative care. However, a systematic review of observational studies of the use of NIV for patients with ARF of any etiology (including 121 patients with COPD of a total of 695 who had declined intubation), suggests that NIV for patients who have declined intubation can delay mortality, but most survivors may require placement in long-term care facilities. The pooled probability of mortality in all patients (ICU, hospital, or 1 year) was 57\% (95\% confidence interval $[\mathrm{CI}] 53 \%-61 \%){ }^{125}$ Single and multicenter observational studies indicate that hospital survival rates in such patients range from $35 \% 126$ to $43 \%,{ }^{127}$ respectively. The greatest benefit is seen in patients with COPD and cardiogenic pulmonary edema (CPE) exacerbations, with up to $70 \%$ surviving to hospital discharge. ${ }^{126,127}$ A higher baseline $\mathrm{PaCO}_{2}$, diagnosis of CPE or COPD, strong cough, and wakefulness were shown to be associated with greater hospital survival. ${ }^{127}$ In a single long-term follow-up study, 37 patients with COPD who declined intubation and were treated with NIV were compared to 43 patients without similar orders. While the 1-year survival 
for patients for whom intubation was still an option was $65 \%$ and higher than when it was not $(30 \%, p<$ 0.001 ), survival was still $30 \%$ in the latter circumstances. ${ }^{128}$ Patients with advanced cancer have a much poorer prognosis, with hospital mortality of $85 \%$ seen in one study. ${ }^{126}$

A recent self-administered survey of physicians (intensivists, pulmonologists) involved in the use of NIV for patients who have declined mechanical ventilation or who are receiving palliative care has helped increase our understanding of the attitudes of clinicians most frequently involved in the application of NIV for these patients. ${ }^{129} \mathrm{We}$ found that, of the 60 intensivists and 44 pulmonologists who responded, more than $80 \%$ stated that they used NIV for patients with COPD who have declined intubation, while significantly fewer $(60 \%)$ use NIV for patients with underlying malignancy, who develop ARF ( $p<0.001$ for the mean difference). In contrast, only $40 \%$ stated they used NIV for patients who are considered to be in the palliative phase with ARF. Independent predictors of the frequency of stated use of NIV by physicians for patients with DNR orders were: number of available NIV machines and the ability of NIV to relieve dyspnea. The ability of NIV to relieve dyspnea was associated with physician use of NIV where the focus was on palliation. ${ }^{129}$ Many intensivists and pulmonary physicians state that they use NIV for patients with ARF who have a DNR status, most often to treat potentially reversible causes such as COPD and CHF. While NIV can be effective in the short term, both in milder and more advanced phases of COPD, we need to look further at the goals of NIV near the end-of-life, and whether these goals are understood by all involved and achieved in practice. ${ }^{129}$

\section{CONCLUSIONS}

The provision of quality palliative care as COPD progresses to its final phases needs to begin, not when dyspnea becomes intractable in the terminal stages, but earlier, when physicians would not be surprised if their patient died in the next 12 months. Patients, families, pulmonologists, and the palliative care team can work in synergy to provide both traditional optimal medical therapy and more innovative approaches to patient education. There should be particular emphasis on informed decision-making around resuscitation preferences and other EOL issues. Patients will benefit from improved self-management, a planned approach to dyspnea (including use of the "Dyspnea Ladder") and to exacerbations of COPD, including novel concepts such as a breathlessness intervention service or crisis intervention at home, and the option of noninvasive ventilation for acute exacerbations or palliation for a time limited trial.

Palliative care is extending its traditional boundaries to encompass more patients with advanced COPD. We should ensure that they, and all other patients with complex and troubling symptoms that diminish the quality of living through the final years, will benefit from the highest quality evidence-based integrated and interdisciplinary model of care that we can provide.

\section{REFERENCES}

1. Gore JM, Brophy CJ, Greenstone MA: How well do we care for patients with end stage chronic obstructive pulmonary disease (COPD)? A comparison of palliative care and quality of life in COPD and lung cancer. Thorax 2000;55:1000-1006.

2. Solano JP, Gomes B, Higginson IJ: A comparison of symptom prevalence in far advanced cancer, AIDS, heart disease, chronic obstructive pulmonary disease and renal disease. J Pain Symptom Manage 2006;31:58-69.

3. Edmonds P, Karlsen S, Khan S, Addington-Hall J: A comparison of the palliative care needs of patients dying from chronic respiratory diseases and lung cancer. Palliat Med 2001;15:287-295.

4. Lacasse Y, Brooks D, Goldstein RS: Trends in the epidemiology of COPD in Canada, 1980 to 1995. COPD and Rehabilitation Committee of the Canadian Thoracic Society. Chest 1999;116:306-313.

5. Respiratory Disease in Canada. Canadian Institute for Health Information, Canadian Lung Association, Health Canada, Statistics Canada. 2001.

6. Murray CJ, Lopez AD. Mortality by cause for eight regions of the world: Global Burden of Disease Study. Lancet 1997;349:1269-1276.

7. Au DH, Udris EM, Fihn SD, McDonell MB, Curtis JR: Differences in health care utilization at the end of life among patients with chronic obstructive pulmonary disease and patients with lung cancer. Arch Intern Med 2006;166:326-331.

8. Bailey PH: The dyspnea-anxiety-dyspnea cycle-COPD patients' stories of breathlessness: "It's scary /when you can't breathe." Qual Health Res 2004;14:760-78.

9. Jones I, Kirby A, Ormiston P, Loomba Y, Chan KK, Rout J, Nagle J, Wardman L, Hamilton S: The needs of patients dying of chronic obstructive pulmonary disease in the community. Fam Pract 2004;21:310-313.

10. Elkington H, White P, Addington-Hall J, Higgs R, Edmonds P: The healthcare needs of chronic obstructive pulmonary disease patients in the last year of life. Palliat Med 2005;19:485-491.

11. Elkington $\mathrm{H}$, White P, Addington-Hall J, Higgs R, Pettinari C: The last year of life of COPD: A qualitative study of symptoms and services. Respir Med 2004; 98:439-445. 
12. Shah S, Blanchard M, Tookman A, Jones L, Blizard R, King M: Estimating needs in life threatening illness: A feasibility study to assess the views of patients and doctors. Palliat Med 2006;20:205-210.

13. Luddington L, Cox S, Higginson I, Livesley B: The need for palliative care for patients with non-cancer diseases: A review of the evidence. Int J Palliat Nurs 2001;7: 221-226.

14. O'Donnell DE, Aaron S, Bourbeau J, Hernandez P, Marciniuk D, Balter M, Ford G, Gervais A, Goldstein R, Hodder R, Maltais F, Road J; Canadian Thoracic Society: Canadian Thoracic Society recommendations for management of chronic obstructive pulmonary disease-2003. Can Respir J 2003;10(Suppl A):11A-65A.

15. Abrahm JL, Hansen-Flaschen J: Hospice care for patients with advanced lung disease. Chest 2002;121:220-229.

16. Claessens MT, Lynn J, Zhong Z, Desbiens NA, Phillips RS, Wu AW, Harrell FE Jr, Connors AF Jr: Dying with lung cancer or chronic obstructive pulmonary disease: Insights from SUPPORT. Study to Understand Prognoses and Preferences for Outcomes and Risks of Treatments. J Am Geriatr Soc 2000;48(5 Suppl):S146-153.

17. Elkington H, White P, Higgs R, Pettinari CJ: GPs' views of discussions of prognosis in severe COPD. Fam Pract 2001;18:440.

18. Guthrie SJ, Hill KM, Muers ME: Living with severe COPD. A qualitative exploration of the experience of patients in Leeds. Respir Med 2001;95:196-204.

19. Selecky PA, Eliasson CA, Hall RI, Schneider RF, Varkey B, McCaffree DR: Palliative and end-of-life care for patients with cardiopulmonary diseases: American College of Chest Physicians position statement. Chest 2005;12: 3599-3610.

20. Lynn J, Ely EW, Zhong Z, McNiff KL, Dawson NV, Connors A, Desbiens NA, Claessens M, McCarthy EP: Living and dying with chronic obstructive pulmonary disease. J Am Geriatr Soc 2000;48(5 Suppl):S91-S100.

21. Tranmer JE, Heyland D, Dudgeon D, Groll D, Squires-Graham M, Coulson K: Measuring the symptom experience of seriously ill cancer and noncancer hospitalized patients near the end of life with the memorial symptom assessment scale. J Pain Symptom Manage 2003;25:420-429.

22. Lunney JR, Lynn J, Foley DJ, Lipson S, Guralnik JM: Patterns of functional decline at the end of life. JAMA 2003;289:2387-2392.

23. Heffner JE, Barbieri C: End-of-life care preferences of patients enrolled in cardiovascular rehabilitation programs. Chest 2000;117:1474-1481.

24. Rocker G, Heyland D, Groll D, Dodek P, Kutsogianis D, Lazar N: Meeting the needs of patients with end stage COPD: A multicentre study. Am J Respir Crit Care Med 2004;169:A50.

25. Fried TR, Bradley EH: What matters to seriously ill older persons making end-of-life treatment decisions?: A qualitative study. J Palliat Med 2003;6:237-244.

26. Oliver SM: Living with failing lungs: The doctor-patient relationship. Fam Pract 2001;18:430-439.

27. Santo Tomas LH, Varkey B: Improving health-related quality of life in chronic obstructive pulmonary disease. Curr Opin Pulmon Med 2004;10:120-127.
28. Mulcahy P, Buetow S, Osman L, Coster G, Bray Y, White $\mathrm{P}$, Elkinton H: GPs' attitudes to discussing prognosis in severe COPD: An Auckland (NZ) to London (UK) comparison. Fam Pract 2005;22:538-540.

29. Knauft E, Nielsen EL, Engelberg RA, Patrick DL, Curtis JR: Barriers and facilitators to end-of-life care communication for patients with COPD. Chest 2005;127:21882196.

30. Grbich C, Maddocks I, Parker D, Brown M, Willis E, Piller N, Hofmeyer A: Identification of patients with noncancer diseases for palliative care services. Palliat Support Care 2005;3:5-14.

31. Coventry PA, Grande GE, Richards DA, Todd CJ: Prediction of appropriate timing of palliative care for older adults with non-malignant life-threatening disease: A systematic review. Age Ageing 2005;34:218-227.

32. Kite S, Jones K, Tookman A: Specialist palliative care and patients with noncancer diagnoses: The experience of a service. Palliat Med 1999;13:477-484.

33. Murray SA, Boyd K, Kendall M, Worth A, Benton TF, Clausen H: Dying of lung cancer or cardiac failure: Prospective qualitative interview study of patients and their carers in the community. BMJ 2002;325:929.

34. Hansen-Flaschen J: Chronic obstructive pulmonary disease: The last year of life. Respir Care 2004;49:90-97.

35. Almagro P, Calbo E, Ochoa de Echaguen A, Barreiro B, Quintana S, Heredia JL, Gaurau J: Mortality after hospitalization for COPD. Chest 2002;121:1441-1448.

36. Domingo-Salvany A, Lamarca R, Ferrer M, GarciaAymerich J, Alonso J, Felez M, Khalaf A, Marrades RM, Monso E, Serra-Batlles J, Anto JM: Health-related quality of life and mortality in male patients with chronic obstructive pulmonary disease. Am J Respir Crit Care Med 2002;166:680-685.

37. Fan VS, Curtis JR, Tu SP, McDonell MB, Fihn SD: Using quality of life to predict hospitalization and mortality in patients with obstructive lung diseases. Chest 2002; 122:429-436.

38. Nishimura K, Izumi T, Tsukino M, Oga T: Dyspnea is a better predictor of 5-year survival than airway obstruction in patients with COPD. Chest 2002;121:1434-1440.

39. Connors AF Jr, Dawson NV, Thomas C, Harrell FE Jr, Desbiens N, Fulkerson WJ, Kussin P, Bellamy P, Goldman L, Knaus WA: Outcomes following acute exacerbation of severe chronic obstructive lung disease. The SUPPORT investigators (Study to Understand Prognoses and Preferences for Outcomes and Risks of Treatments). Am J Respir Crit Care Med 1996;154(4 Pt 1):959-967.

40. Heyland DK, Dodek P, Rocker G, Groll D, Gafni A, Pichora D, Shortt S, Tranmer J, Lazar N, Kutsogiannis J, Lam M; Canadian Researchers End-of-Life Network (CARENET): What matters most in end-of-life care: Perceptions of seriously ill patients and their family members. CMAJ 2006;174:627-633.

41. Celli BR, Cote CG, Marin JM, Casanova C, Montes de Oca M, Mendez RA, Pinto Plata V, Cabral HJ: The bodymass index, airflow obstruction, dyspnea, and exercise capacity index in chronic obstructive pulmonary disease. $\mathrm{N}$ Engl J Med.2004;350:1005-1012. 
42. Soler-Cataluna JJ, Martinez-Garcia MA, Roman Sanchez P, Salcedo E, Navarro M, Ochando R: Severe acute exacerbations and mortality in patients with chronic obstructive pulmonary disease. Thorax 2005;60:925-931.

43. Roy DJ: Palliative care without borders. J Palliat Care 2005;21:131-132.

44. Rocker G: Palliative care for the next decade: Moving beyond cancer. J Palliat Care 2005;21:140-141.

45. Curtis JR, Engelberg RA, Nielsen EL, Au DH, Patrick DL. Patient-physician communication about end-of-life care for patients with severe COPD. Eur Respir J 2004;24:200-205.

46. Heyland DK, Groll D, Rocker G, Dodek P, Gafni A, Tranmer J, Pichora D, Lazar N, Kutsogiannis J, Shortt S, Lam M; Canadian Researchers at the End of Life Network (CARENET): End-of-life care in acute care hospitals in Canada: a quality finish? J Palliat Care 2005;21: 142-150.

47. Nisar M, Earis JE, Pearson MG, Calverley PM: Acute bronchodilator trials in chronic obstructive pulmonary disease. Am Rev Respir Dis 1992;146:555-559.

48. National Emphysema Treatment Trial Research Group: Patients at high risk of death after lung-volume-reduction surgery. N Engl J Med 2001;345:1075-1083.

49. Ferreira G, Feuerman M, Spiegler P: Results of an 8-week, outpatient pulmonary rehabilitation program on patients with and without chronic obstructive pulmonary disease. J Cardiopulm Rehabil 2006;26:54-60.

50. Jennings AL, Davies AN, Higgins JP, Gibbs JS, Broadley KE: A systematic review of the use of opioids in the management of dyspnoea. Thorax 2002;57:939-944.

51. Booth S, Farquhar M, Gysels M, Bausewein C, Higginson IJ: The impact of a breathlessness intervention service (BIS) on the lives of patients with intractable dyspnea: A qulaitative phase 1 study. Palliat Support Care 2006;4:287-293.

52. Medical Research Council: A framework for development and evaluation of RCTs for complex interventions to improve health. London: MRC, 2000.

53. Bausewein C, Farquhar M, Booth S, Gysels M, Higginson IJ: Measurement of breathlessness in advanced disease: A systematic review. Respir Med 2007;101:399_ 410.

54. Schunemann HJ, Griffith L, Jaeschke R, Goldstein R, Stubbing D, Austin P, Guyatt GH: A comparison of the original chronic respiratory questionnaire with a standardized version. Chest 2003;124:1421-1429.

55. Rutten-van Molken M, Roos B, Van Noord JA: An empirical comparison of the St George's Respiratory Questionnaire (SGRQ) and the Chronic Respiratory Disease Questionnaire (CRQ) in a clinical trial setting. Thorax 1999;54:995--1003.

56. Dyspnea. Mechanisms, assessment, and management: A consensus statement. American Thoracic Society. Am J Respir Crit Care Med 1999;159:321-340.

57. Schunemann HJ, Goldstein R, Mador MJ, McKim D, Stahl E, Puhan M, Griffith LE, Grant B, Austin P, Collins $\mathrm{R}$, Guyatt GH: A randomised trial to evaluate the self-administered standardised chronic respiratory questionnaire. Eur Respir J 2005;25:31-40.
58. Schunemann HJ, Griffith L, Jaeschke R, Goldstein R, Stubbing D, Guyatt GH: Evaluation of the minimal important difference for the feeling thermometer and the St. George's Respiratory Questionnaire in patients with chronic airflow obstruction. J Clin Epidemiol 2003;56: 1170-1176.

59. Schunemann HJ, Griffith L, Stubbing D, Goldstein R, Guyatt GH: A clinical trial to evaluate the measurement properties of 2 direct preference instruments administered with and without hypothetical marker states. Med Decis Making 2003;23:140-149.

60. Schwartzstein RM, Lahive K, Pope A, Weinberger SE, Weiss JW: Cold facial stimulation reduces breathlessness induced in normal subjects. Am Rev Respir Dis 1987; 136:58-61.

61. O'Donnell DE, Aaron S, Bourbeau J, Hernandez P, Marciniuk D, Balter M, Ford G, Gervais A, Goldstein R, Hodder R, Maltais F, Road J: State of the Art Compendium: Canadian Thoracic Society recommendations for the management of chronic obstructive pulmonary disease. Can Respir J;2004;11(Suppl B):7B-59B.

62. Abernethy AP, Currow DC, Frith P, Fazekas BS, McHugh A, Bui C: Randomised, double blind, placebo controlled crossover trial of sustained release morphine for the management of refractory dyspnoea. BMJ 2003;327:523-528.

63. Foral PA, Malesker MA, Huerta G, Hilleman DE: Nebulized opioids use in COPD. Chest 2004;125:691-694.

64. Walsh TD, Rivera NI, Kaiko R: Oral morphine and respiratory function amongst hospice inpatients with advanced cancer. Support Care Cancer 2003;11:780-784.

65. Abramson MJ, Crockett AJ, Frith PA, McDonald CF: COPDX: An update of guidelines for the management of chronic obstructive pulmonary disease with a review of recent evidence. Med J Aust 2006;184:342-345.

66. Heffner JE, Fahy B, Hilling L, Barbieri C: Attitudes regarding advance directives among patients in pulmonary rehabilitation. Am J Respir Crit Care Med 1996;154(6 Pt 1):1735-1740.

67. McNeely PD, Hebert PC, Dales RE, O'Connor AM, Wells G, McKim D, Sullivan KE: Deciding about mechanical ventilation in end-stage chronic obstructive pulmonary disease: How respirologists perceive their role. CMAJ 1997; 156:177-183.

68. Sullivan KE, Hebert PC, Logan J, O’Connor AM, McNeely PD: What do physicians tell patients with end-stage COPD about intubation and mechanical ventilation? Chest 1996;109:258-264.

69. Curtis JR, Wenrich MD, Carline JD, Shannon SE, Ambrozy DM, Ramsey PG: Patients' perspectives on physician skill in end-of-life care: Differences between patients with COPD, cancer, and AIDS. Chest 2002;122:356-362.

70. Gaber KA, Barnett M, Planchant Y, McGavin CR: Attitudes of 100 patients with chronic obstructive pulmonary disease to artificial ventilation and cardiopulmonary resuscitation. Palliat Med 2004;18:626-629.

71. Johnston SC, Pfeifer MP, McNutt R: The discussion about advance directives. Patient and physician opinions regarding when and how it should be conducted. End of Life Study Group. Arch Intern Med 1995;155: 1025-1030. 
72. Wilson KG, Aaron SD, Vandemheen KL, Hebert PC, McKim DA, Fiset V, Graham ID, Sevigny E, O'Connor AM: Evaluation of a decision aid for making choices about intubation and mechanical ventilation in chronic obstructive pulmonary disease. Patient Educ Couns 2005; 57:88-95.

73. Dales RE, O'Connor A, Hebert P, Sullivan K, McKim D, Llewellyn-Thomas $\mathrm{H}$ : Intubation and mechanical ventilation for COPD: Development of an instrument to elicit patient preferences. Chest 1999;116:792-800.

74. Mikkelsen RL, Middelboe T, Pisinger C, Stage KB: Anxiety and depression in patients with chronic obstructive pulmonary disease (COPD). A review. Nord J Psychiatry 2004;58:65-70.

75. van Ede L, Yzermans CJ, Brouwer HJ: Prevalence of depression in patients with chronic obstructive pulmonary disease: A systematic review. Thorax 1999;54:688-692.

76. Kim HF, Kunik ME, Molinari VA, Hillman SL, Lalani S, Orengo CA, Petersen NJ, Nahas Z, Goodnight-White S: Functional impairment in COPD patients: the impact of anxiety and depression. Psychosomatics 2000;41:465-471.

77. Ferrer M, Alonso J, Morera J, Marrades RM, Khalaf A, Aguar MC, Plaza V, Prieto L, Anto JM: Chronic obstructive pulmonary disease stage and health-related quality of life. The Quality of Life of Chronic Obstructive Pulmonary Disease Study Group. Ann Intern Med 1997; 127:1072-1079.

78. Lacasse Y, Rousseau L, Maltais F: Prevalence of depressive symptoms and depression in patients with severe oxygen-dependent chronic obstructive pulmonary disease. J Cardiopulm Rehabil 2001;21:80-86.

79. McSweeny AJ, Grant I, Heaton RK, Adams KM, Timms RM: Life quality of patients with chronic obstructive pulmonary disease. Arch Intern Med 1982;142:473-478.

80. Di Marco F, Verga M, Reggente M, Maria Casanova F, Santus P, Blasi F, Allegra L, Centanni S: Anxiety and depression in COPD patients: The roles of gender and disease severity. Respir Med 2006;100:1767-1774.

81. Gudmundsson G, Gislason T, Janson C, Lindberg E, Suppli Ulrik C, Brondum E, Nieminen MM, Aine T, Hallin $\mathrm{R}$, Bakke P: Depression, anxiety and health status after hospitalisation for COPD: A multicentre study in the Nordic countries. Respir Med 2006;100:87-93.

82. Light RW, Merrill EJ, Despars JA, Gordon GH, Mutalipassi LR: Prevalence of depression and anxiety in patients with COPD. Relationship to functional capacity. Chest 1985;87:35-38.

83. Borson S, McDonald GJ, Gayle T, Deffebach M, Lakshminarayan S, VanTuinen C: Improvement in mood, physical symptoms, and function with nortriptyline for depression in patients with chronic obstructive pulmonary disease. Psychosomatics 1992;33:190-201.

84. Runo JR, Ely EW: Treating dyspnea in a patient with advanced chronic obstructive pulmonary disease. West J Med 2001;175:197-201.

85. Manning HL: Dyspnea treatment. Respir Care 2000;45: 1342-1350; discussion 1350-1354.

86. Stage KB, Middelboe T, Pisinger C: Depression and chronic obstructive pulmonary disease (COPD). Impact on survival. Acta Psychiatr Scand 2005;111:320-323.
87. Stapleton RD, Nielsen EL, Engelberg RA, Patrick DL, Curtis JR: Association of depression and life-sustaining treatment preferences in patients with COPD. Chest 2005; 127:328-334.

88. Elofsson LC, Ohlen J: Meanings of being old and living with chronic obstructive pulmonary disease. Palliat Med 2004;18:611-618.

89. Garuti G, Cilione C, Dell'Orso D, Gorini P, Lorenzi MC, Totaro L, Cirelli G, Clini E: Impact of comprehensive pulmonary rehabilitation on anxiety and depression in hospitalized COPD patients. Monaldi Arch Chest Dis 2003; 59:56-61.

90. Booth S, Silvester S, Todd C: Breathlessness in cancer and chronic obstructive pulmonary disease: Using a qualitative approach to describe the experience of patients and carers. Palliat Support Care 2003;1:337-344.

91. Nici L, Donner C, Wouters E, Zuwallack R, Ambrosino N, Bourbeau J, Carone M, Celli B, Engelen M, Fahy B, Garvey C, Goldstein R, Gosselink R, Lareau S, MacIntyre N, Maltais F, Morgan M, O'Donnell D, Prefault C, Reardon J, Rochester C, Schols A, Singh S, Troosters T; ATS/ERS Pulmonary Rehabilitation Writing Committee: American Thoracic Society/European Respiratory Society statement on pulmonary rehabilitation. Am J Respir Crit Care Med 2006;173:1390-1413.

92. Bourbeau J, Julien M, Maltais F, Rouleau M, Beaupre A, Begin R, Renzi P, Nault D, Borycki E, Schwartzman K, Singh R, Collet JP; Chronic Obstructive Pulmonary Disease axis of the Respiratory Network Fonds de la Recherche en Sante du Quebec: Reduction of hospital utilization in patients with chronic obstructive pulmonary disease: A disease-specific self-management intervention. Arch Intern Med 2003;163:585-591.

93. Lacasse Y, Brosseau L, Milne S, Martin S, Wong E, Guyatt GH, Goldstein RS: Pulmonary rehabilitation for chronic obstructive pulmonary disease. Cochrane Database Syst Rev 2002(3):CD003793.

94. O'Donnell DE, D'Arsigny C, Webb KA: Effects of hyperoxia on ventilatory limitation during exercise in advanced chronic obstructive pulmonary disease. Am J Respir Crit Care Med 2001;163:892-898.

95. Emtner M, Porszasz J, Burns M, Somfay A, Casaburi R: Benefits of supplemental oxygen in exercise training in nonhypoxemic chronic obstructive pulmonary disease patients. Am J Respir Crit Care Med 2003;168:1034-1042.

96. Garrod R, Paul EA, Wedzicha JA: Supplemental oxygen during pulmonary rehabilitation in patients with COPD with exercise hypoxaemia. Thorax 2000;55:539-543.

97. McDonald CF, Blyth CM, Lazarus MD, Marschner I, Barter CE: Exertional oxygen of limited benefit in patients with chronic obstructive pulmonary disease and mild hypoxemia. Am J Respir Crit Care Med 1995;152(5 Pt 1):1616-1619.

98. Hernandez P, Maltais F, Gursahaney A, Leblanc P, Gottfried SB: Proportional assist ventilation may improve exercise performance in severe chronic obstructive pulmonary disease. J Cardiopulm Rehabil 2001;21:135-142.

99. O’Donnell DE, Sanii R, Giesbrecht G, Younes M: Effect of continuous positive airway pressure on respiratory sensation in patients with chronic obstructive pulmonary dis- 
ease during submaximal exercise. Am Rev Respir Dis 1988;138:1185-1191.

100. Keilty SE, Ponte J, Fleming TA, Moxham J: Effect of inspiratory pressure support on exercise tolerance and breathlessness in patients with severe stable chronic obstructive pulmonary disease. Thorax 1994;49:990-994.

101. Bianchi L, Foglio K, Porta R, Baiardi R, Vitacca M, Ambrosino N: Lack of additional effect of adjunct of assisted ventilation to pulmonary rehabilitation in mild COPD patients. Respir Med 2002;96:359-367.

102. Hawkins P, Johnson LC, Nikoletou D, Hamnegard CH, Sherwood R, Polkey MI, Moxham J: Proportional assist ventilation as an aid to exercise training in severe chronic obstructive pulmonary disease. Thorax 2002; 57:853-859.

103. Bourbeau J, Nault D, Dang-Tan T: Self-management and behaviour modification in COPD. Patient Educ Couns 2004;52:271-277.

104. Heffner JE, Fahy B, Barbieri C: Advance directive education during pulmonary rehabilitation. Chest. 1996;109(2): 373-379.

105. Haggerty MC, Stockdale-Woolley R, Nair S: Respi-Care. An innovative home care program for the patient with chronic obstructive pulmonary disease. Chest 1991;100: 607-612.

106. Watson PB, Town GI, Holbrook N, Dwan C, Toop LJ, Drennan CJ: Evaluation of a self-management plan for chronic obstructive pulmonary disease. Eur Respir J 1997;10:1267-1271.

107. Emanuel EJ, Fairclough DL, Slutsman J, Emanuel LL: Understanding economic and other burdens of terminal illness: The experience of patients and their caregivers. Ann Intern Med 2000;132:451-459.

108. Grunfeld E, Coyle D, Whelan T, Clinch J, Reyno L, Earle CC, Willan A, Viola R, Coristine M, Janz T, Glossop R: Family caregiver burden: Results of a longitudinal study of breast cancer patients and their principal caregivers. CMAJ 2004;8;170:1795.

109. Nijboer C, Tempelaar R, Sanderman R, Triemstra M, Spruijt RJ, van den Bos GA: Cancer and caregiving: The impact on the caregiver's health. Psychooncology 1998; 7:3-13.

110. Nijboer C, Triemstra M, Tempelaar R, Mulder M, Sanderman R, van den Bos GA: Patterns of caregiver experiences among partners of cancer patients. Gerontologist 2000;40:738-746.

111. Higginson IJ, Finlay IG, Goodwin DM, Hood K, Edwards AG, Cook A, Douglas HR, Normand CE: Is there evidence that palliative care teams alter end-of-life experiences of patients and their caregivers? J Pain Symptom Manage 2003;25:150-168.

112. Harding R, Higginson IJ: What is the best way to help caregivers in cancer and palliative care? A systematic literature review of interventions and their effectiveness. Palliat Med 2003;17:63-74.

113. Bailey PH: Death stories: Acute exacerbations of chronic obstructive pulmonary disease. Qual Health Res 2001; 11:322-338.

114. Seamark DA, Blake SD, Seamark CJ, Halpin DM: Living with severe chronic obstructive pulmonary disease
(COPD): Perceptions of patients and their carers. An interpretative phenomenological analysis. Palliat Med 2004; 18:619-625.

115. Hughes SL, Weaver FM, Giobbie-Hurder A, Manheim L, Henderson W, Kubal JD, Ulasevich A, Cummings J; Department of Veterans Affairs Cooperative Study Group on Home-Based Primary Care: Effectiveness of team-managed home-based primary care: A randomized multicenter trial. JAMA 2000;284:2877-2885.

116. Ram FS, Wedzicha JA, Wright J, Greenstone M: Hospital at home for patients with acute exacerbations of chronic obstructive pulmonary disease: Systematic review of evidence. BMJ 2004;329:315.

117. Hermiz O, Comino E, Marks G, Daffurn K, Wilson S, Harris M: Randomised controlled trial of home based care of patients with chronic obstructive pulmonary disease. BMJ 2002;325:938.

118. Kwok T, Lum CM, Chan HS, Ma HM, Lee D, Woo J: A randomized, controlled trial of an intensive community nurse-supported discharge program in preventing hospital readmissions of older patients with chronic lung disease. J Am Geriatr SoC. 2004;52:1240-1246.

119. Rabow MW, Dibble SL, Pantilat SZ, McPhee SJ. The comprehensive care team: A controlled trial of outpatient palliative medicine consultation. Arch Intern Med. 2004; 164:83-91.

120. Aiken LS, Butner J, Lockhart CA, Volk-Craft BE, Hamilton G, Williams FG: Outcome evaluation of a randomized trial of the PhoenixCare intervention: Program of case management and coordinated care for the seriously chronically ill. J Palliat Med 2006;9:111-126.

121. Keenan SP, Sinuff T, Cook DJ, Hill NS: Which patients with acute exacerbation of chronic obstructive pulmonary disease benefit from noninvasive positive-pressure ventilation? A systematic review of the literature. Ann Intern Med 2003;138:861-870.

122. Benhamou D, Girault C, Faure C, Portier F, Muir JF: Nasal mask ventilation in acute respiratory failure. Experience in elderly patients. Chest 1992;102:912-917.

123. Meduri GU, Fox RC, Abou-Shala N, Leeper KV, Wunderink RG: Noninvasive mechanical ventilation via face mask in patients with acute respiratory failure who refused endotracheal intubation. Crit Care Med 1994;22:1584-1590.

124. Benditt JO. Noninvasive ventilation at the end of life. Respir Care 2000;45:1376-1381; discussion 1381-1384.

125. Sinuff T, Adhikari NKJ, Geerts S, Curtis JR, Cook DJ, Keenan SP, Hill NS. Noninvasive Ventilation (NIV) for Patients with Acute Respiratory Failure (ARF) in the Setting of a Do-not-intubate (DNI) Decision: Systematic Review. Proceedings of the American Thoracic Society 2007;147:A787.

126. Schettino G, Altobelli N, Kacmarek RM: Noninvasive positive pressure ventilation reverses acute respiratory failure in select "do-not-intubate" patients. Crit Care Med 2005;33:1976-1982.

127. Levy M, Tanios MA, Nelson D, Short K, Senechia A, Vespia J, Hill NS: Outcomes of patients with do-not-intubate orders treated with noninvasive ventilation. Crit Care Med 2004;32:2002-2007.

128. Chu CM, Chan VL, Wong IW, Leung WS, Lin AW, Che- 
ung KF: Noninvasive ventilation in patients with acute hypercapnic exacerbation of chronic obstructive pulmonary disease who refused endotracheal intubation. Crit Care Med 2004;32:372-377.

129. Sinuff T, Burns KEA, Eva K, Adhikari NKJ, Keenan SP, Rocker G, Hill N, Patel R, Mehta S, Heels-Ansdell D, Heyland D, Kacmarek R, Cook DJ. Noninvasive ventilation (NIV) for acute respiratory failure (ARF) near the end-of-life (EOL). Proc Am Thorac Soc 2005;2:A810.
Address reprint requests to: Graeme M. Rocker, M.H.Sc., D.M. \#4457 Halifax Infirmary 1796 Summer Street Halifax B3H 3 A7 Canada

E-mail:gmrocker@dal.ca 